\title{
Discrepancies between the Doses of Cholecystokinin or Caerulein-Stimulating Exocrine and Endocrine Responses in Perfused Isolated Rat Pancreas
}

\author{
Makoto Otsuki, Choitsu Sakamoto, Hosai YuU, Mitsuo Maeda, Soichiro \\ Morita, Atsuhi Ohki, Noboru Kobayashi, Katsuhiro Terashi, Kuniyasu \\ OKano, and Shigeaki Baba, The Second Department of Internal Medicine, \\ Kobe University School of Medicine, Kusunoki-cho, Ikuta-ku, Kobe, 650, Japan
}

A B S T R A C T The effects of highly purified natural porcine cholecystokinin (CCK) and synthetic caerulein on the rate of flow of pancreatic juice, the rate of output of amylase, and the rate of release of immunoreactive insulin (IRI) and immunoreactive glucagon (IRG) were simultaneously investigated in the isolated perfused rat pancreas.

The maximal flow rate of pancreatic juice was obtained with concentrations of CCK ranging from 0.5 to $10 \mathrm{mU} / \mathrm{ml}$, whereas amylase output was maximal at CCK concentrations from 1 to $10 \mathrm{mU} / \mathrm{ml}$. Caerulein at concentrations of $0.05-1 \mathrm{ng} / \mathrm{ml}$ induced a similar maximal flow rate and amylase secretion. Supramaximal stimulatory concentrations of these peptides resulted in lower rates of release of fluid and amylase than with the maximally effective concentrations. Stimulation of IRI and IRG release was elicited only with concentrations of peptides supramaximal for effects on the exocrine responses.

The demonstration of very similar discrepancies between the doses of caerulein required to elicit maximal exocrine responses and those required to elicit endocrine responses provide strong evidence that the pattern of the effect of the porcine CCK is accounted for by CCK itself.

Although caerulein had no influence on IRI response when superimposed on 100 or $150 \mathrm{mg} / 10 \hat{\mathrm{m}} \mathrm{ml}$ glucose stimulation, preperfusion of caerulein led to a significant enhancement of IRI response to a subsequent glucose stimulation in both phases. The augmentation effect was completely separate from the direct IRI-stimulating effect of caerulein, because the CCKlike peptide requires no glucose for insulinotropic action.

Received for publication 25 May 1978 and in revised form 13 November 1978.
Because the concentrations of the peptides necessary for stimulation of endocrine responses were inhibitory in their effects on exocrine responses, it may be inferred that it is unlikely that the endocrine effect is physiologically important, though the results of caerulein for augmenting glucose-stimulated IRI release suggests a possible role for CCK in carbohydrate metabolism.

\section{INTRODUCTION}

Earlier studies have shown that cholecystokinin $(\mathrm{CCK})^{1}$ elevates blood levels of insulin and glucagon in man and in animals (1-4), and stimulates the release of both hormones from the isolated perfused pancreas of the $\operatorname{dog}(5-7)$ and the rat (8). Recently, these effects of the endocrine pancreas previously attributed to CCK have been ascribed to contaminating gastric inhibitory polypeptide (GIP) present in impure preparations of CCK $(9,10)$. In fact, Dupré and Beck (11), and other investigators (12-14) found no such effects of the hormone when highly purified CCK was used. More recently, however, synthetic COOH-terminal octapeptide of CCK has been shown to stimulate the release of insulin and glucagon both in vivo (15) and in vitro $(6,7)$. These conflicting results are probably caused by the fact that pure natural preparation of the hormone has not yet been studied in "physiological" doses. The present studies were, therefore, designed to determine the effects of CCK on the exocrine and endocrine pancreas in the isolated perfused preparation of rat pancreas with a highly purified natural porcine CCK as a stimulating agent. Synthetic caerulein was also studied as a stimulating agent because the $\mathrm{COOH}$ -

\footnotetext{
${ }^{1}$ Abbreviations used in this paper: CCK, cholecystokinin, GIP, gastric inhibitory polypeptide; IRG, immunoreactive glucagon; IRI, immunoreactive insulin.
} 
terminal pentapeptide of caerulein is identical with that of mammalian gastrin and CCK, the molecule also has a sulphated tryptophan residue at position seven from the COOH-terminus, and it contains no contaminating peptides. Moreover, it has been proven that the biological actions of the peptide closely resemble those of porcine CCK (16-18). In this experimental system, factors other than the direct effect of hormonal stimulus on the pancreas, such as autonomous nervous system or alteration of blood glucose concentrations, could be eliminated while simultaneously determining pancreatic exocrine and endocrine function.

\section{METHODS}

Pancreases from male Wistar rats, weighing $250-280 \mathrm{~g}$, fed ad libitum were isolated and perfused according to the technique of Kanno (19). The pancreas was perfused with Krebs-Ringer bicarbonate solution with 4.3\% dextran T-70 (Pharmacia Fine Chemicals, Uppsala, Sweden), $0.25 \%$ bovine serum albumin (fraction V, Armour Pharmaceutical Co., Phoenix, Ariz.), and $50 \mathrm{mg} / 100 \mathrm{ml}$ glucose, gassed constantly with $95 \% \mathrm{O}_{2}, 5 \% \mathrm{CO}_{2}$ mixture to achieve pH 7.4. Perfusate was administered into superior mesenteric and celiac artery via a nonrecirculating open circuit. Flow rate was kept at $\cong 2.0 \mathrm{ml} / \mathrm{min}$ by making minor changes in arterial pressure with the aid of a micro-tubing pump (type MP 101, Tokyo Rikakikai Co. Ltd., Tokyo, Japan). The pancreas was performed for an equilibration period of at least $40 \mathrm{~min}$ before samples were measured for their hormone content. Total portal effluent was collected in chilled tubes at 60-s intervals for measurement of insulin and glucagon concentrations.

Pure natural porcine CCK ( $1 \mathrm{mg}: 3,500 \mathrm{U}$, Gastro-Intestinal Hormone [G.I.H.] Research Units, Karolinska Institute, Stockholm, Sweden) was applied by changing the medium reservoir. The concentration of CCK is expressed in Ivy dog units per milliliter solution (20). When the effect of CCK was studied, a $2(0-\mathrm{min}$ basal period was followed by a 2() -min stimulatory period and then a 20 -min recovery period.

Pure natural porcine CCK contained no detectable glucagon-like immunoreactivity, secretin, or vasoactive intestinal polypeptide when assayed by radioimmunoassay, though the contamination of GIP could not be tested because of the lack of availability of reliable GIP assay system. Ipp et al. (6), however, recently reported that CCK from the G.I.H. Research Units in Stockholm contained $<2 \%$ immunoreactive GIP.

The relationships between the dose of caerulein (Kyowa Hakko Kogyo, Ltd., Tokyo, Japan) and the rate of flow of pancreatic juice, the rate of amylase output, and the rate of immunoreactive insulin (IRI) and immunoreactive glucagon (IRG) release were investigated under the same conditions used in the experiments with pure natural porcine CCK to exclude the possible contribution of GIP on IRI and IRG release. The concentration of caerulein is expressed in nanograms per milliliter.

To determine whether CCK-like peptide might require high glucose levels, as does GIP, for insulinotropic action, an infusion of caerulein at a concentration known to be effective at $50 \mathrm{mg} / 100 \mathrm{ml}$ glucose was administered in the absence of glucose. In other experiments, a substimulatory concentration of caerulein for effects on endocrine responses was superimposed on 100 and $150 \mathrm{mg} / 100 \mathrm{ml}$ glucose stimulation.

IRI was measured by polyethylene glycol radioimmunoassay (21). IRG was determined by radioimmunoassay with a talc absorption technique (22) with antiserum $30 \mathrm{~K}$ (purchased from University of Texas Southwestern Medical School, Dallas, Tex.). Rat insulin and porcine glucagon were used as standards in IRI and IRG assay, respectively.

Flow rate of pancreatic juice and amylase output, and IRI and IRG responses were measured simultaneously to evaluate the effect of CCK and caerulein on exocrine and endocrine pancreas. For measurement of the pancreatic exocrine secretions, a calibrated capillary tube was attached to the free end of the pancreatic cannula, which was inserted into the distal end of the common duct at a point shortly before its entrance to duodenum and tied in place. The proximal end of the bile duct was ligated. Every $10 \mathrm{~min}$ the capillary tube was replaced and the flow rate of the pancreatic juice was measured. The sample of juice was diluted with $5 \%$ bovine serum albumin solution, and amylase activity was determined by a chromogenic method with blue-dyed starch polymer (23). Amylase output was expressed as Somogyi units/10 min.

Data are represented as mean $\pm S E M$. Statistical analysis was performed with the Student's $t$ test. Differences with $P$ values of $<0.05$ were considered statistically significant.

\section{RESULTS}

The time-course of pancreatic juice flow and amylase output in response to perfusion with different concentrations of CCK is shown in Fig. 1. Maximal flow rate was obtained with doses of CCK ranging from 0.5 to $10 \mathrm{mU} / \mathrm{ml}$, whereas amylase output was maximal from 1 to $10 \mathrm{mU} / \mathrm{ml}$. A further increase in the concentration of CCK resulted in decreasing responses of both pancreatic juice flow and amylase output. Post-stimulatory rebound secretion of amylase and fluid occurred after omission of $100 \mathrm{mU} / \mathrm{ml}$ or greater doses of CCK.

The results presented in Fig. 2 indicate that the stimulation of IRI and IRG release was elicited only with concentrations of CCK supramaximal for effects on the exocrine responses. An infusion of CCK at a maximally effective concentration for exocrine functions $(0.5-10 \mathrm{mU} / \mathrm{ml})$ yielded no significant increase in IRI and IRG output over preloading and control levels (basal control levels: IRI $<0.25 \mathrm{ng} / \mathrm{ml}$; IRG, $65.8 \pm 10.7$ $\mathrm{pg} / \mathrm{ml})$. The peak values of IRI and IRG in response to $100 \mathrm{mU} / \mathrm{ml} \mathrm{CCK}$ were $6.0 \pm 1.3 \mathrm{ng} / \mathrm{ml}$ (preloading level: $<0.25 \mathrm{ng} / \mathrm{ml}$ ) and $277.5 \pm 73.8 \mathrm{pg} / \mathrm{ml}$ (preloading level: $61.7 \pm 9.0 \mathrm{pg} / \mathrm{ml}$ ), respectively.

The IRI and IRG responses to each dose of CCK were over by $5 \mathrm{~min}$ despite the continued infusion of CCK for $20 \mathrm{~min}$; the response began within $60 \mathrm{~s}$ of the initiation of the stimulation, reached peak at 1-2 min, and declined rapidly thereafter (Fig. 3).

Very similar discrepancies between the doses of synthetic caerulein required to elicit maximal exocrine responses and those required to elicit endocrine responses were observed. A maximal response in flow rate and amylase output was obtained with doses of caerulein ranging from 0.05 to $1 \mathrm{ng} / \mathrm{ml}$. Further increase of the perfused concentrations was followed by lower rates of release of fluid and enzyme; pancreatic 


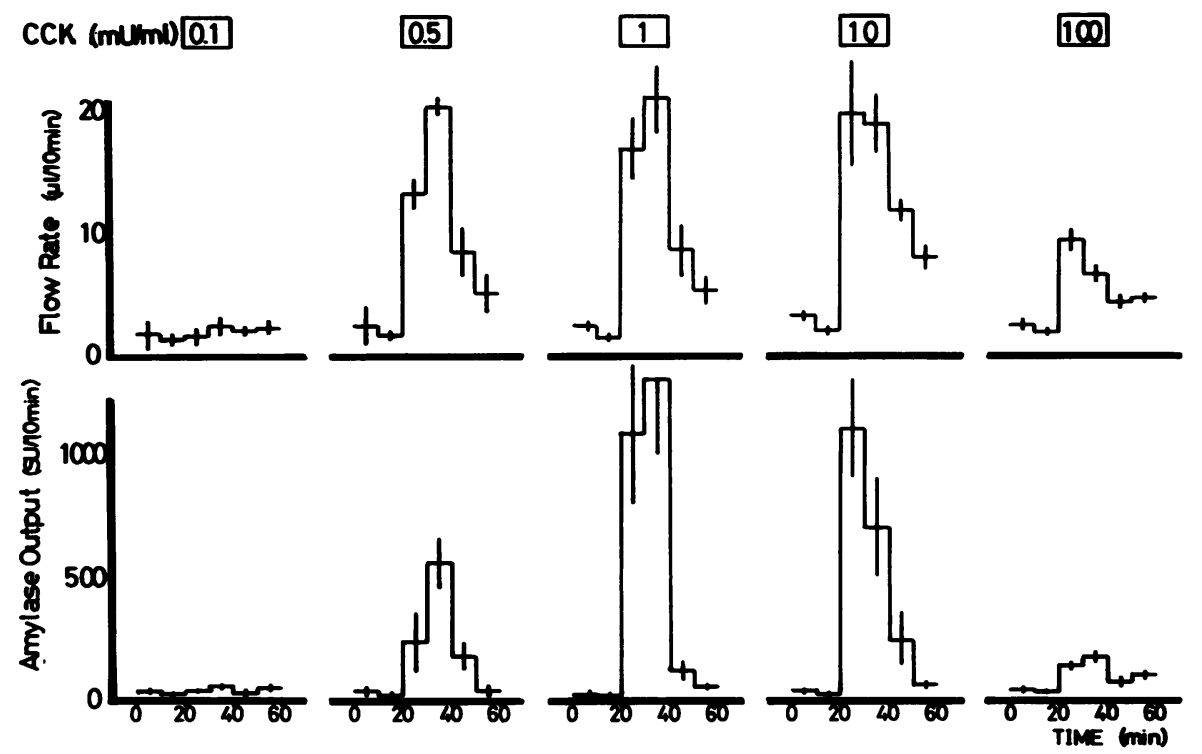

FIGURE 1 Time-course of pancreatic juice flow and amylase output in response to a 20-min perfusion with different concentrations of CCK. Each value represents the mean \pm SEM of eight experiments.

exocrine responses to $1,000 \mathrm{ng} / \mathrm{ml}$ caerulein was as low as the basal levels. On the other hand, the threshold dose of caerulein capable of producing an appreciable increase of IRI and IRG release was $1 \mathrm{ng} / \mathrm{ml}$. The endocrine responses were transitory and proportional to the doses up to $100 \mathrm{ng} / \mathrm{ml}$ (Table I, Fig. 4).

The secretory responses of IRI and IRG to $10 \mathrm{ng} / \mathrm{ml}$ caerulein in a glucose-free medium were almost identical to those induced by the same dose of caerulein in the presence of $50 \mathrm{mg} / 100 \mathrm{ml}$ glucose (Fig. 5).

Substimulatory concentrations of caerulein for effects on endocrine responses $(0.1 \mathrm{ng} / \mathrm{ml})$ were super-

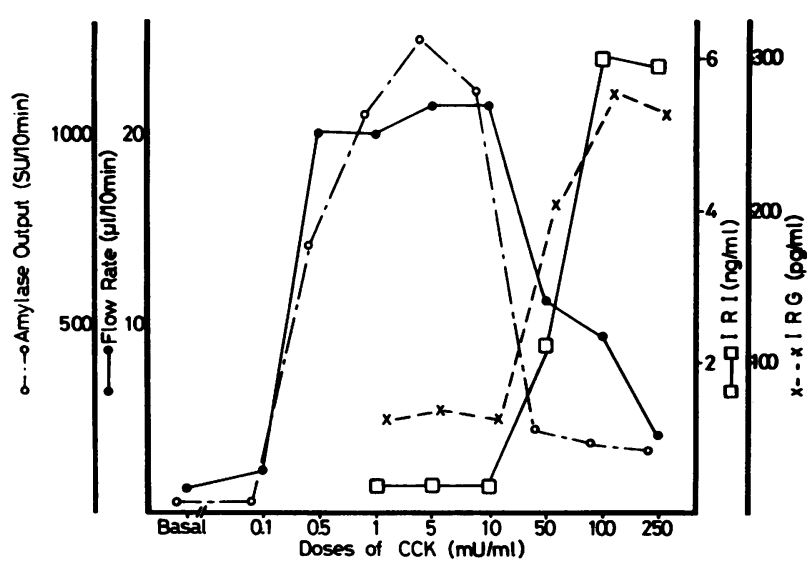

FIGURE 2 Relationship between concentration of CCK and the peak flow rate of pancreatic juice, peak amylase output, and the maximal IRI and IRG concentrations in the pancreatic effluent. Each value represents the mean of eight experiments. imposed for $10 \mathrm{~min}$ on 50,100 , and $150 \mathrm{mg} / 100 \mathrm{ml}$ glucose stimulation. Neither the first nor the second phase of IRI release was elicited by this dose of caerulein. When the pancreas was exposed to caerulein, and subsequently to glucose, the IRI responses to glucose stimulation were significantly greater in both phases than those to control infusion without preperfusion of caerulein (Fig. 6). The peak IRI value in response to $100 \mathrm{mg} / 100 \mathrm{ml}$ glucose with or without preexposure to $0.1 \mathrm{ng} / \mathrm{ml}$ caerulein was $33.3 \pm 13.7$ and 6.9 $\pm 1.7 \mathrm{ng} / \mathrm{ml}$, respectively. Whereas the peak value in the acute IRI response to $150 \mathrm{mg} / 100 \mathrm{ml}$ glucose with or without pre-exposure to $0.1 \mathrm{ng} / \mathrm{ml}$ caerulein was $59.0 \pm 8.0$ and $38.3 \pm 10.4 \mathrm{ng} / \mathrm{ml}$. The augmentation effect was more pronounced in the second phase of the IRI response, whereas IRG concentrations in the perfusate were suppressed by these amounts of glucose. Despite these changes of endocrine responses, fluid and amylase releases in response to $0.1 \mathrm{ng} / \mathrm{ml}$ caerulein were unaffected.

Perfused isolated rat pancreas was temporarily exposed to medium with no added glucose followed by restoration of glucose medium $(100 \mathrm{mg} / 100 \mathrm{ml})$ to elicit endogenous IRI or IRG release comparable to that induced by high concentrations of CCK or caerulein. $1 \mathrm{mU} / \mathrm{ml} \mathrm{CCK}$, a maximal stimulatory concentration for effects on exocrine responses, was infused simultaneously in both situations to evaluate the effect of transitory increases in IRI or IRG concentrations on CCK-induced pancreatic exocrine secretions. In spite of the increased IRI or IRG levels in the perfusate, the rate of flow and the rate of amylase output in response to $1 \mathrm{mU} / \mathrm{ml} \mathrm{CCK}$ in both situations were nearly the 


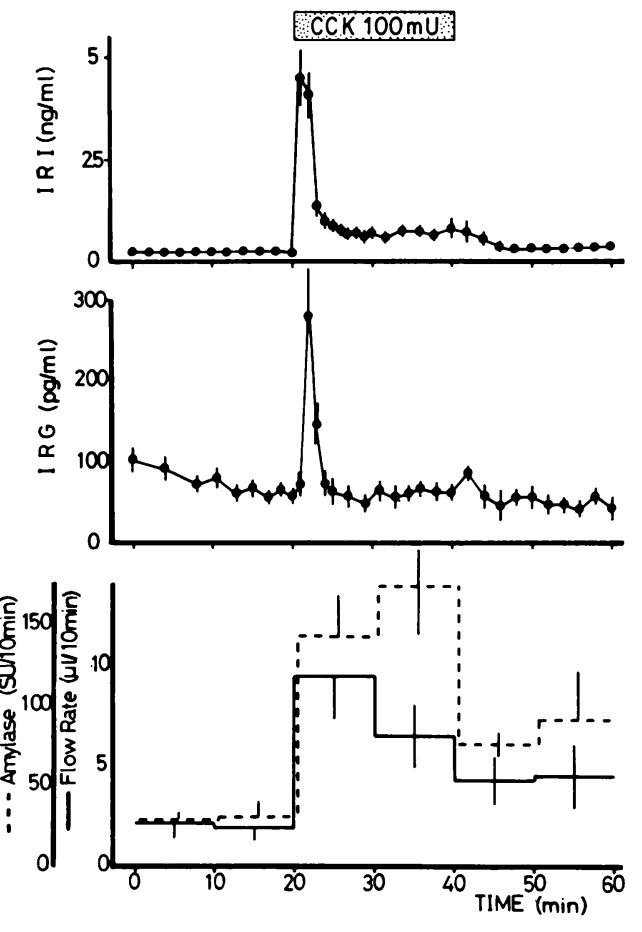

FIGURE 3 Effect of $100 \mathrm{mU} / \mathrm{ml} \mathrm{CCK}$ on IRI and IRG release in the pancreatic effluent and the flow rate of pancreatic juice and amylase output. Each value represents the mean \pm SEM of eight experiments.

same as those obtained in the presence of $50 \mathrm{mg} / 100 \mathrm{ml}$ glucose, where neither IRI nor IRG was elevated (Fig. 7).

\section{DISCUSSION}

CCK is an established stimulator of exocrine pancreatic function $(24,25)$ and has been reported by some to also stimulate insulin and glucagon release (1-8). The interpretation of the latter observations are unclear, however, because of the fact that most studies have used impure CCK now known to contain $\operatorname{GIP}(9,10)$ and because the plasma levels of CCK to which effects of exogenous CCK should be compared are unknown. The present study was, therefore, designed to reinvestigate the question with attention on both areas.

Highly purified porcine CCK is confirmed here to be capable of, not only stimulating the flow rate of pancreatic juice and amylase secretion, but also eliciting IRI and IRG release from the isolated perfused rat pancreas. However, discrepancies between the doses of CCK eliciting exocrine and endocrine effects were found.

It is important to exclude the possibility that the stimulation of IRI and IRG release demonstrated with highly purified CCK is caused in some part by GIP, because it has been reported that pure natural porcine CCK obtainable from G.I.H. Laboratories in Stockholm has contained $1-2 \%$ GIP by weight (6). The effectiveness of GIP as a stimulant of IRI release in the perfused rat pancreas was observed mainly in the second phase of secretion (about $10 \mathrm{~min}$ after the initiation of stimulation (26), whereas the effect of CCK on IRI and IRG secretions was transitory; the responses at any doses were over by $5 \mathrm{~min}$ despite the prolonged infusion of CCK. An initial rapid-rise phase of IRI release as observed in the present investigation with CCK, was obtained only with doses of GIP $>5 \mathrm{ng} / \mathrm{ml}$ in the presence of $8.9 \mathrm{mM}(160 \mathrm{mg} / 100 \mathrm{ml})$ glucose (26). From these observations it seems unlikely that GIP is involved in endocrine responses of the pancreas to highly purified natural porcine CCK. Moreover, the demonstration of very similar discrepancies between the doses of caerulein required to elicit maximal exocrine

TABLE I

Relationship between Concentrations of Caerulein and the Peak Flow Rate of Pancreatic Juice, Peak Amylase Output, and the Maximal IRI and IRG Concentrations in the Pancreatic Effluent

\begin{tabular}{|c|c|c|c|c|c|}
\hline \multirow[b]{2}{*}{ Dose } & \multirow{2}{*}{$\begin{array}{l}\text { Number of } \\
\text { animals }\end{array}$} & \multicolumn{2}{|c|}{$\begin{array}{l}\text { Maximum pancreatic exocrine } \\
\text { secretion }\end{array}$} & \multicolumn{2}{|c|}{$\begin{array}{l}\text { Maximum pancreatic endocrine } \\
\text { secretion }\end{array}$} \\
\hline & & Pancreatic juice & Amylase output & IRI & IRG \\
\hline$n g / m l$ & & $\mu l i 10 \mathrm{~min}$ & $\begin{array}{c}\text { Somogyi units/ } \\
10 \mathrm{~min}\end{array}$ & $n g / m l$ & $p g / m l$ \\
\hline Control & 12 & $2.2 \pm 0.4$ & $18.0 \pm 2.8$ & $<0.25$ & $104.9 \pm 11.1$ \\
\hline 0.01 & 10 & $3.5 \pm 0.9$ & $45.2 \pm 10.4$ & $<0.25$ & $106.0 \pm 4.0$ \\
\hline 0.05 & 10 & $35.0 \pm 4.5$ & $1,406.5 \pm 65.2$ & $<0.25$ & $123.0 \pm 12.0$ \\
\hline 0.1 & 10 & $44.7 \pm 1.2$ & $1,826.7 \pm 209.5$ & $<0.25$ & $112.9 \pm 12.2$ \\
\hline 1 & 12 & $34.1 \pm 3.3$ & $2,017.7 \pm 73.2$ & $1.5 \pm 0.2$ & $324.7 \pm 24.7$ \\
\hline 10 & 18 & $8.5 \pm 0.9$ & $298.4 \pm 35.0$ & $13.9 \pm 3.2$ & $629.8 \pm 118.9$ \\
\hline 100 & 8 & $5.9 \pm 1.5$ & $54.1 \pm 9.8$ & $19.8 \pm 3.2$ & $897.8 \pm 138.7$ \\
\hline 1,000 & 8 & $2.4 \pm 0.3$ & $14.7 \pm 2.8$ & $21.9 \pm 2.8$ & $821.6 \pm 197.2$ \\
\hline
\end{tabular}

Values are mean \pm SEM. 

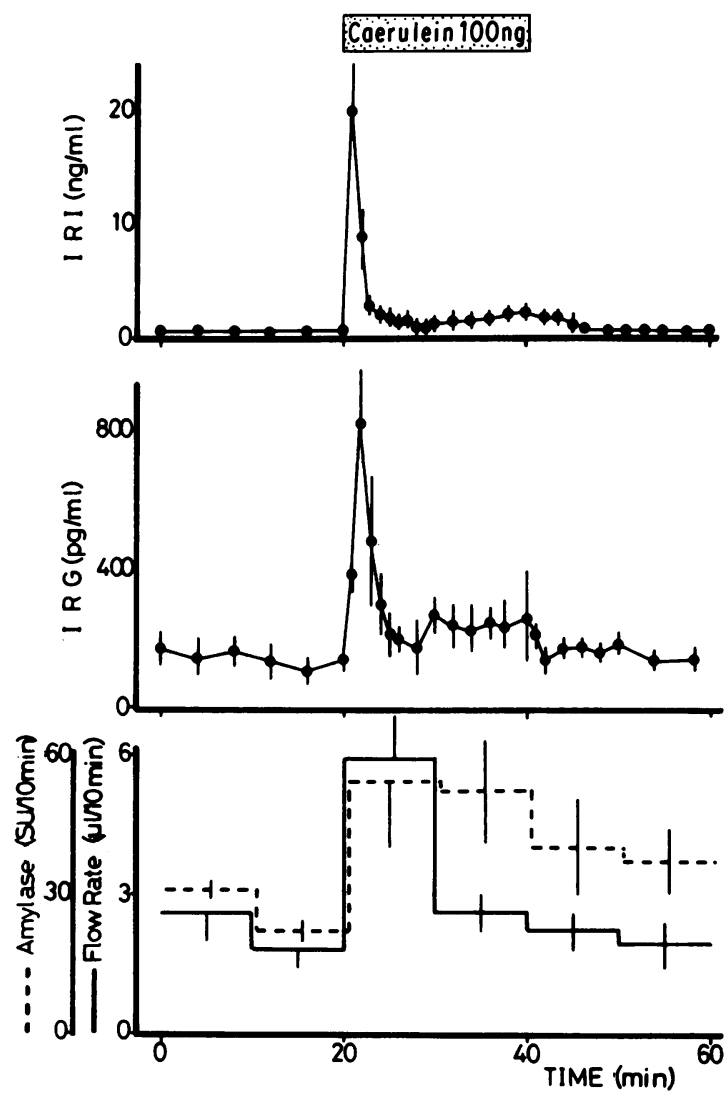

FIgURE 4 Effect of $100 \mathrm{ng} / \mathrm{ml}$ caerulein on IRI and IRG release in the pancreatic effluent and the flow rate of pancreatic juice and amylase output. Each value represents the mean \pm SEM of eight experiments.

responses and those required to elicit endocrine responses provide strong evidence that the pattern of effect of the porcine CCK is accounted for by CCK itself.

IRI release could not be elicited by a small dose of caerulein $(0.1 \mathrm{ng} / \mathrm{ml})$, independent of the perfusing glucose concentrations. However, pre-exposure of the pancreas to these doses of caerulein led to a significant enhancement of IRI responses to a subsequent glucose stimulation. The augmentation effect was completely separate from the direct IRI-stimulating effect of caerulein, because caerulein requires no glucose for insulinotropic action. Pre-perfused caerulein might have made more IRI readily available to glucose stimulation, either by enlarging the size of the glucoseresponsive pool or by increasing the islet sensitivity to glucose, as has been noted with secretin (27).

These results of caerulein for augmenting glucosestimulated IRI release suggests a possible role for CCK in carbohydrate metabolism, though the concentrations of the peptides necessary for stimulation of endocrine responses were inhibitory in their effects on exocrine pancreas. Discrepancies between the doses of CCK or caerulein eliciting exocrine and endocrine effects have raised the question as to whether or not the apparently inhibitory effects of high concentrations of the peptides on pancreatic exocrine responses are attributable to effects of IRI and IRG release.

The inhibitory effect of glucagon on exocrine pancreatic secretion is well known $(28,29)$, whereas insulin has been demonstrated to potentiate the CCKinduced amylase release from the isolated rat pancreas (30). As the isolated pancreas is perfused with a nonrecirculating medium at a constant flow rate of 2.0 $\mathrm{ml} / \mathrm{min}$, it is unlikely that the transient increase of IRG concentration in the perfusate in response to supramaximal doses of CCK or caerulein is responsible for the reduced pancreatic exocrine responses to a 20 -min stimulation with these peptides. Although the procedure used does not simulate the condition of the experiments with the test peptides, which elicit concurrent release of IRI and IRG, neither IRI nor IRG inhibited the exocrine responses to $1 \mathrm{mU} / \mathrm{ml} \mathrm{CCK}$. These results suggest that the transient increase of IRI or IRG concentrations may not be responsible for the reduced flow rate of pancreatic juice and enzyme secretion with supramaximal doses. It has been postulated that the decrease in exocrine secretions observed with high doses of CCK or caerulein indicates inhibition of release of enzymes from the pancreas, in view of the post-stimulatory rebound secretion of enzymes (31).

Recently, however, Ipp et al. $(6,7)$ have demon-

Caerulein $10 \mathrm{ng} / \mathrm{ml}$
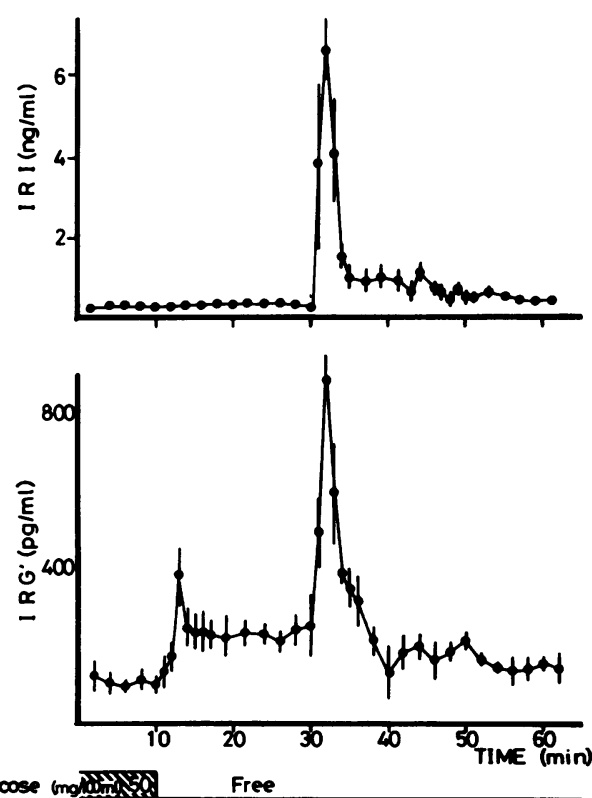

FIGÜR 5 Effect of $10 \mathrm{ng} / \mathrm{ml}$ caerulein on IRI and IRG release in a glucose-free medium. Glucose concentration in the perfusion medium was quickly changed from $50 \mathrm{mg} / 100 \mathrm{ml}$ to 0 at $10 \mathrm{~min}$. After equilibration for $20 \mathrm{~min}, 10 \mathrm{ng} / \mathrm{ml}$ caerulein was infused over a period of $20 \mathrm{~min}$ in the absence of glucose. Each value represents the mean $\pm S E M$ of five experiments. 


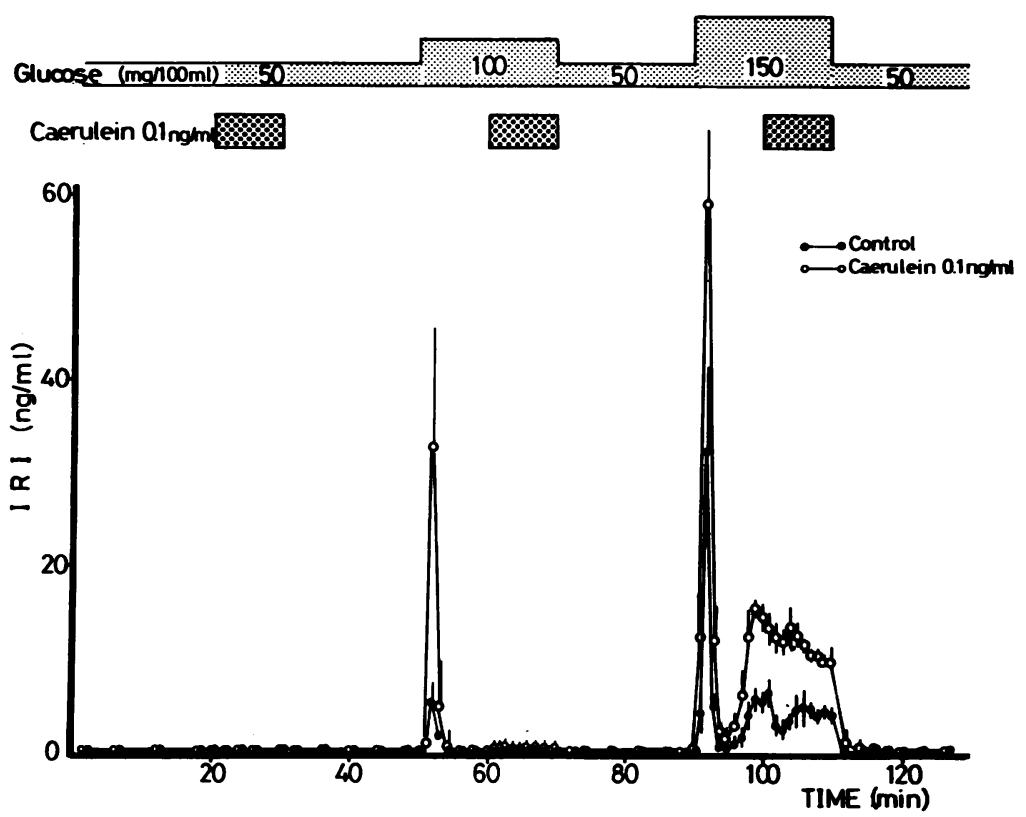

FIGURE 6 Effect of $0.1 \mathrm{ng} / \mathrm{ml}$ caerulein on IRI responses to 50,100 , and $150 \mathrm{mg} / 100 \mathrm{ml}$ glucose. 0.1 $\mathrm{ng} / \mathrm{ml}$ caerulein was superimposed for $10 \mathrm{~min}$ on 50,100 , and $150 \mathrm{mg} / 100 \mathrm{ml}$ glucose stimulation. Each value represents the mean \pm SEM of five experiments.
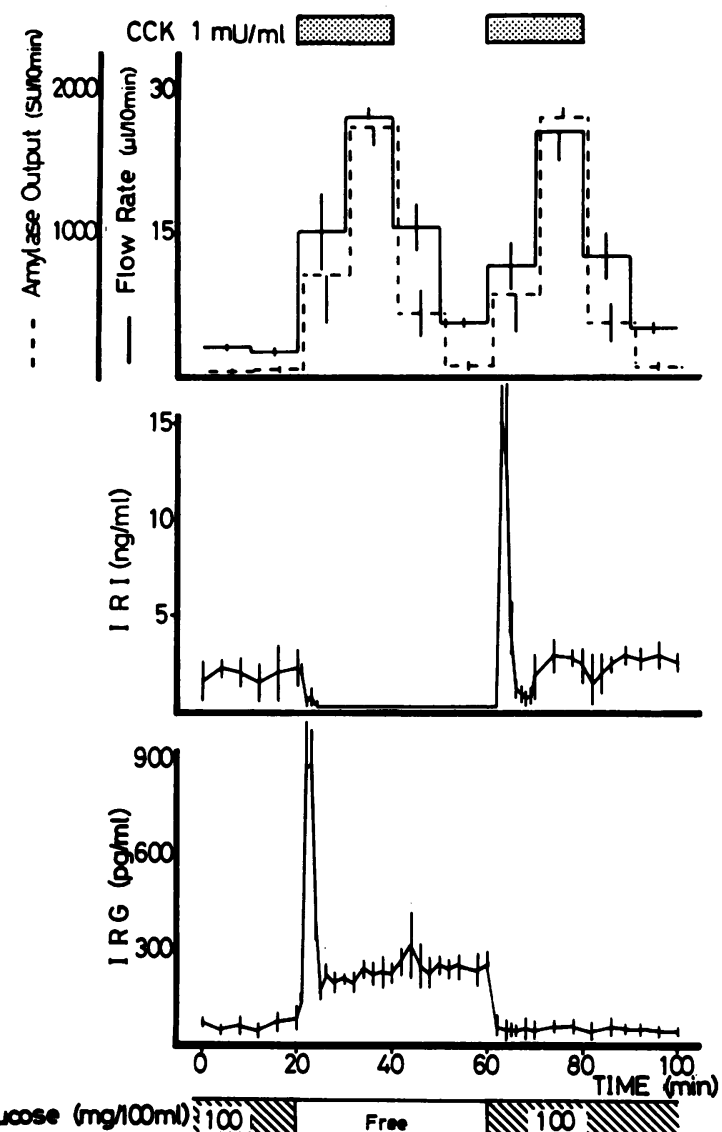

FIGURE 7 Effect of transiently increased endogenous IRI or IRG concentrations in the perfusate on $1 \mathrm{mU} / \mathrm{ml}$ CCKstimulated pancreatic exocrine secretions. Each value represents the mean $\pm S E M$ of six experiments. strated that CCK and synthetic COOH-terminal octapeptide CCK elicit a biphasic somatostatin release by the perfused canine pancreas. If the inhibitory effects upon exocrine pancreas occur at physiological concentrations of somatostatin, it may be conceivable that the elevated somatostatin concentration in the perfusate reduces the effects of CCK on pancreatic exocrine function.

None of the previous investigations has examined the relationship between pancreatic exocrine and endocrine secretions as influenced by variable doses of CCK. Studies presented here show that physiological comparison to the exocrine pancreas is of importance because its dose-response relation should be related to levels of CCK perfusing the pancreas, which in any case may be different from systemic levels. Because the concentrations of the peptides necessary for stimulation of endocrine responses were inhibitory in their effect on exocrine responses, it may be inferred that it is unlikely that the endocrine effect is physiologically important, though a possible role for the peptides in carbohydrate metabolism has been suggested.

The results of the present investigations lead to the conclusion that CCK elicits IRI and IRG release from the pancreas, in addition to stimulating the flow rate of pancreatic juice and amylase secretion. However, it is yet premature to assign any physiologic cytotropic function to CCK until more accurate methods for its assay become available.

\section{REFERENCES}

1. Meade, R. C., H. A. Kneubuhler, W. J. Schulte, and J. J. Barboiak. 1967. Stimulation of insulin secretion by pancreozymin. Diabetes. 16: 141-144. 
2. Unger, R. H., H. Ketterer, J. Dupre, and A. M. Eisentraut. 1967. The effects of secretin, pancreozymin and gastrin on insulin and glucagon secretion in anesthetized dogs. $J$. Clin. Invest. 46: 630-645.

3. Buchanan, K. D., J. E. Vance, A. Morgan, and R. H. Williams. 1968. Effect of pancreozymin on insulin and glucagon levels in blood and bile. Am. J. Physiol. 215: 1293-1298.

4. Dupre, J., J. D. Curtis, R. H. Unger, R. W. Wadell, and J. C. Beck. 1969. Effect of secretin, pancreozymin, or gastrin on the response of the endocrine pancreas to administration of glucose or arginine in man. J. Clin. Invest. 48: 745-757.

5. Iversen, J. 1971. Secretion of glucagon from the isolated perfused canine pancreas. J. Clin. Invest. 50: 2123-2136.

6. Ipp, E., R. E. Dobbs, A. Arimura, W. Vale, V. Harris, and R. H. Unger. 1977. Release of immunoreactive somatostatin from the pancreas in response to glucose, amino acids, pancreozymin-cholecystokinin, and tolbutamide. J. Clin. Invest. 60: 760-765.

7. Ipp, E., R. E. Dobbs, V. Harris, A. Arimura, W. Vale, and R. H. Unger. 1977. The effects of gastrin, gastric inhibitory polypeptide, secretin, and the octapeptide of cholecystokinin upon immunoreactive somatostatin release by the perfused canine pancreas. J. Clin. Invest. 60: 1216-1219.

8. Fussganger, R. D., K. Straub, R. Goeberna, P. Jaros, K. E. Shroder, S. Raptis, and E. F. Pfeiffer. 1969. Primary secretion of insulin and secondary release of glucagon from isolated perfused rat pancreas following stimulation with pancreozymin. Horm. Metab. Res. 1: 224-227.

9. Dupre, J., S. A. Ross, D. Watson, and J. C. Brown. 1973. Stimulation of insulin secretion by gastric inhibitory polypeptide in man.J. Clin. Endocrinol. Metab. 37: 826-828.

10. Rabinovitch, A., and J. Dupre. 1974. Effects of the gastric inhibitory polypeptide present in impure pancreozymincholecystokinin on plasma insulin and glucagon in the rat. Endocrinology. 94: 1139-1144.

11. Dupre, J., and J. C. Beck. 1966. Stimulation of release of insulin by an extract of intestinal mucosa. Diabetes. 15: 555-559.

12. Boyns, D. R., and R. J. Jarrett. 1967. Intestinal hormones and plasma insulin: an insulinotrophic action of secretin. $\mathrm{Br}$. Med. J. II: 676-678.

13. Hedner, P., G. Persson, and D. Ursing. 1975. Insulin release in fasting man induced by impure but not by pure preparations of cholecystokinin. Acta Med. Scand. 197: 109-112.

14. Rabinovitch, A., and J. Dupre. 1972. Insulinotropic and glucagonotropic activities in crude preparation of cholecystokinin-pancreozymin. Clin. Res. 20: 945.

15. Frame, C. M., M. B. Davidson, and R. A. L. Sturdevant. 1975. Effects of the octapeptide of cholecystokinin on insulin and glucagon secretion in the dog. Endocrinology. 97: 549-553.
16. Bertaccini, G.., G. de Caro, R. Endean, V. Erspamer, and M. Impicciatore. 1968. The action of caerulein on the smooth muscles of the gastrointestinal tract and the gall bladder. Br. J. Pharmacol. 34: 291-310.

17. Beraccini, G., R. Enden, V. Erspamer, and M. Impicciatore. 1968. The actions of caerulein on gastric acid secretion of the dog and the rat. Br. J. Pharmacol. 34: 311-329.

18. Bertaccini, G., G. de Caro, R. Endean, V. Erspamer, and M. Impicciatore. 1969. The actions of caerulein on pancreatic secretion of the dog and biliary secretion of the dog and rat. Br. J. Pharmacol. 37: 185-197.

19. Kanno, T. 1972. Calcium-dependent amylase release and electrophysiological measurements in cells of the pancreas. J. Physiol. (Lond.). 226: 353-371.

20. Ivy, A. C., and H. M. Janecek. 1959. Assay of Jorpes-Mutt secretin and cholecystokinin. Acta Physiol. Scand. 45: 220-230.

21. Desbuquois, B., and G. D. Aurbach. 1971. Use of polyethyleneglycoal to separate free and antibody-bound peptide hormones in radioimmunoassay. J. Clin. Endocrinol. Metab. 33: 732-738.

22. Aguilar-Parada, E., E. M. Eisentraut, and R. H. Unger. 1969. Pancreatic glucagon secretion in normal and diabetic subjects. Am. J. Med. Sci. 257: 415-419.

23. Ceska, M., K. Birath, and B. Brown. 1969. A new and rapid method for the clinical determination of a-amylase activities in human serum and urine. Clin. Chim. Acta. 26: 437-444.

24. Ivy, A. C., and E. Oldberg. 1928. A hormone mechanism for gall bladder contraction and evacuation. Am.J. Physiol. 86: $599-613$.

25. Harper, A. A., and H. S. Raper. 1943. Pancreozymin, a stimulant of the secretion of pancreatic enzyme in extracts of the small intestine. J. Physiol. (Lond.). 102: $115-125$.

26. Pederson, R. A., and J. C. Brown. 1976. The insulinotropic action of gastric inhibitory polypeptide in the perfused isolated rat pancreas. Endocrinology. 99: 780-785.

27. Lerner, R. L. 1977. The augmentation effect of secretin on the insulin response to known stimuli: Specificity for glucose. J. Clin. Endocrinol. Metab. 45: 1-9.

28. Dyck, W. P., J. Rudick, B. Hoexter, and H. D. Janowitz. 1969. Influence of glucagon on pancreatic exocrine secretion. Gastroenterology. 56: 531-537.

29. Fontana, G., P. L. Costa, R. Tessari, and G. Labo. 1975. Effect of glucagon on pure human exocrine pancreatic secretion. Am. J. Gastroenterol. 63: 490-494.

30. Kanno, T., and S. Saito. 1976. The potentiating influence of insulin on pancreozymin-induced hyperpolarization and amylase release in the pancreatic acinar cell. J. Physiol (Lond.). 261: 505-521.

31. Wormsley, K. G. 1969. A comparison of the response to secretin, pancreozymin and a combination of these hormones in man. Scand. J. Gastroenterol. 4: 413-417. 